\title{
Hein Willemse Om ruim in Afrika te leef
}

Hein Willemse is'n professor in letterkunde en hoof van die Departement Afrikaans, Universiteit van Pretoria. Sy jongste publikasie is More than Brothers:

Peter Clarke and James Matthews at 70 (2000).

E-pos:willemse@postino.up.ac.za

\section{TO LIVE ABUNDANTLY IN AFRICA}

This article is a revised version of an inaugural lecture delivered at the University of Pretoria on 19 July 2001. The paper considers the future of Departments of Afrikaans following the end of Afrikaner political rule. It is divided into three subsections: a overview of the close affiliation between the Afrikans language, literature and Afrikaner nationalism, as well as the practice of Afrikaans literary criticism; reactions from the Afrikaans speaking community to the demise of Afrikaner political rule and lastly, tentative proposals for the continued development of Departments of Afrikaans. The association between Afrikaans and Afrikaner nationalism became so ingrained that discursively, the language became the exclusive domain of the Afrikaners. The democratisation of 1994 brought about change and weakened the bond between Afrikaner nationalism and the Afrikaans language. Responses to the new dispensation vary. One such response is an attempt at redefining Afrikaner identity, encompassing those whose roles in the formation of the Afrikaans language were previously undervalued (such as black, principally coloured, Afrikaans speakers). Other responses support an overarching South African identity. These public debates have corollaries in the debates on Afrikaans literature. The author argues that conscious steps must be undertaken to actively develop links with other African, southern and South African literatures; while at the same time institutionalised literary models, approaches and the demands of contemporary cultural practices must be re-evaluated.

\section{1}

Die Afrikaanse letterkunde is in terme van Oosterse en Westerse letterkundige tradisies baie jonk. In verhouding met ander Afrikaletterkundes is dit een van die min letterkundes wat ten opsigte van taal, produksie, en lesersgetalle sedert sy ontstaan volgehoue groei, en in bepaalde tye, selfs skouspelagtige opbloei getoon het (sien ook Lindfors, 1997: 121-134). Dié ontwikkeling sou die afgelope eeu of meer in Suid-Afrika en inderdaad in Afrika as geheel as merkwaardig bestempel kon word. Daar sou selfs met reg beweer kon word dat die Afrikaanse letterkunde 'n hoë vlak van volwassenheid en tegniese sofistikasie bereik het.

Die Afrikaanse letterkunde is in wese egter' $n$ etniese letterkunde met' $n$ verwysingsraam wat afgestem is op die Afrikaner- of Afrikaanse kultuursfeer. Dit is ook'n letterkunde wat in sy ontstaan- en ontwikke- 
lingsgang in hoofsaak één deel van daardie potensiële kultuurgemeenskap beskryf of bedien het. ${ }^{1}$

Dit sou nie onvanpas wees om te beweer dat hierdie groei en ontwikkeling in noue verband met die ontplooiing van' $n$ bepaalde etniese nasionalisme staan nie (sien ook Du Toit, 1999: 235). Afrikaans en die Afrikaanse letterkunde staan sentraal in die ontwikkeling van Afrikaner-nasionalisme (sien Willemse, 1992). Ek wil verder die bewering maak dat die Afrikaanse letterkunde, selfs in sy mees kritiese geskrifte, in verhouding tot Afrikaner-nasionalisme gestaan het, omdat dit dikwels die grense van die nasionalisme aangedui het. Adam Lerner (1993: 3) merk tereg op dat "In the multitude of texts through which the concept of the nation travels, it is never on its own. That is, there can be no text which is solely a nationalist text. Thus, the nation is always forging liaisons with other boundary-marking constructs." Afrikaner-nasionalisme vertolk ek hier nie net as' $n$ politieke uitdrukking nie, maar as daardie stelle vormgewende en totaliserende aksies en handelinge wat bydra tot sosiale, politieke en kulturele identiteitsvorming. Met die natuurlike, selfs onproblematiese uitdrukkings wat nasionalismes in die algemeen kenmerk, kon veral blanke Afrikaanssprekendes feitlik onnadenkend en onkrities hul taal en verbandhoudende kulturele praktyke beleef.

Gegewe hierdie agtergrond ontstaan die vraag, wat gebeur met die Afrikaanse letterkunde as een van sy vernaamste steunfaktore, naamlik Afrikaner-nasionalisme in 'n bestaanskrisis is, op die agtergrond gedwing, of ondermyn word? Die afgelope tyd het oorlewing en saambestaan die sentrum van' $n$ debat geword wat teruggaan tot' $n$ tyd toe die Genootskap van Regte Afrikaners Afrikaans tot'n merker van politieke aspirasie verhef het. Die vraag na oorlewing en saambestaan lei tot' $n$ tweede wesensvraag vir hierdie artikel, naamlik wat gebeur met Departemente Afrikaans wanneer die politieke, maar veral ekonomiese mat, onder hulle uitgetrek word?

Ek bied die artikel in drie bewegings aan. Eerstens bespreek ek kortliks die wyse waarop Afrikaans, die Afrikaanse letterkunde en die Afrikaanse literêre praktyk die afgelope eeu of wat uitdrukking gevind het. Daarna bied ek'n oorsig van reaksies ten opsigte van Afrikaans na aanleiding van die verlies van politieke beheer en laastens maak ek'n aantal tentatiewe voorstelle rondom die toekoms van Departemente Afrikaans aan universiteite. 
Om ' $n$ taal te praat, is van die natuurlikste vermoëns van die mens. Om 'n spesifieke taal te praat, is ingegee deur 'n omgewing en sosialisering. Meesal dink die spreker nooit oor sy taal nie. Die praat van 'n eerstetaal is so natuurlik soos 'n asemteug. Maar taal weet ons, beteken veel meer. In koloniale kontekste gebeur dit dikwels dat spanninge bestaan tussen koloniale en inheemse tale, of tussen inheemse tale onderling, veral waar een oorheersend en andere onder politieke of sosiale druk is. In sulke omstandighede moet sprekers dikwels hul taalkeuse rasionaliseer. So moes byvoorbeeld talle swart Afrikaanssprekendes Afrikaans as hul taal rasionaliseer. ${ }^{2}$ Dit maak nie saak wat die uiteindelike keuse was nie. Die vermoedelike ambivalensie oor taal wat hulle ervaar het, moes gerasionaliseer word. Sou geen ambivalensie ervaar word nie, moes ook dit verklaar word. Homi Bhabha (1994: 132) suggereer dat ambivalensie op die moment van ontkenning "produces a strategy for the negotiation of the knowledges of differentiation."

In talle historiese opsigte was die Afrikaans van swart Afrikaanssprekendes byvoorbeeld onderwaardeer en selfs uitgerangeer. Hulle was van huis uit Afrikaans, hulle wêreld is beskryf en omgeef deur Afrikaans. In A.H.M. Scholtz se roman, Vatmaar, verklaar een van die karakters, “Ons het die Engelse taal geleer met wat hulle'n Coloured-mind genoem het en aan Afrikaans gedink as ons eie taal. Afrikaans hoef ons nie te geleer het nie" (Scholtz, 1995: 98). Tog was dit dieselfde taal wat hulle menswees (en dié van ander) beperk en ingekort het. In dieselfde roman vertel die wysgeer-karakter, Ta Vuurmaak, met 'n emosieloosheid van daardie geskiedenis: "Ons, die Griekwas en die Boesmans, is nie mense nie, het die witmense gesê. En hulle het ons gejag soos wild en onse woonplekke binnegestorm en ons doodgemaak asof ons 'n gevaar vir hulle was. Hulle het hulle se honde liewer gehad as ons, die mense wat hulle gehaat het" (Scholtz, 1995: 89).

Dit is die erkenning van verskille wat swart Afrikaanssprekendes se taalkeuse later (dikwels weg van Afrikaans) gedetermineer het. Afrikaans het mettertyd in die diskursiewe realiteit feitlik uitsluitlik die taal van wit Afrikaanssprekendes en die draer van 'n eng gedefinieerde etniese nasionalisme en apartheid geword. As hierdie persepsie nie deur ou apartheidswetgewing of staatsinstellinge of staatsoptrede verstewig is nie, is dit versterk deur die Afrikaanse letterkunde. Vergelyk byvoorbeeld die volgende ietwat oordrewe en veralgeme- 
nende, maar in geheel gesien, tog geldige afwysende uitspraak van Es'kia (Ezekiel) Mphahlele (1974: 14):

[N]o-one can reasonably be blamed for the language he speaks. (...) [A] language commits you to a culture, real or imagined. If you use your political power to shut out your human environment and cage yourself in, your culture must shrink and with it your language. Indeed Afrikaans poetry always brings a picture to mind of a canary in a cage, whose singing is constantly interrupted by the approach of a tethered cat out there. Alternately frantic and playful, but always circumscribed by the walls of the cage. Always a prisoner of fear while still a master of its own cage. As the language, so the culture, and vice versa.

Die noue band tussen die Afrikaner se politieke strewe en die Afrikaanse letterkunde word miskien die klinkendste verwoord deur N.P. van Wyk Louw (1938: 15) in Die dieper reg, geskryf as geleentheidspel by die hoeksteenlegging van die Voortrekkermonument in 1938:

Ek kom om vir 'n volk te pleit

Wat klein naas al die volke staan, -

Dat hulle naam nie sal verklink

En tot die stiltes gans vergaan.

Hierdie verbintenis tussen 'n volk "wat klein naas al die volke staan", die digter as pleitbesorger en die taal as draer van ' $n$ nasionalistiese sentiment vorm "die etiese \& religieuse fundering van ' $n$ kragdadige nasionalisme wat op bloedbewustheid berus" (Louw aangehaal in Steyn, 1998: 246). Na 'n periode van buitelandse verblyf en afstand van die alledaagse Suid-Afrikaanse omgewing sou die einste Louw (1981: 317) later met ' $n$ mate van ontreddering die volgende versreëls in "Nuusberigte 1956" skryf:

Ek het vergeet - nie geweet? - in die dae toe ons jonk was:

Afrikanerskap is nie heilig. Ons wóú dit heilig hê;

Ons wou die volte van menslikheid daaraan gee.

Veral Breyten Breytenbach het in sy poësie en in sy persoon hom volledig teen Afrikaner-nasionalisme uitgespreek. As voorbeeld herinner ek $u$ aan sy donderende verse in "bruin reisbrief" (Breytenbach, 1981: 18):

Wat bly van jou konstruksies oor?

Jou onverdraagsame Kerk, of jou kerke met die vlerke 
wyd van blinde voëls,

jou blindelingse apartheidsléér die Hel in -

(...)

Net die hoop dan barse broer, dat jy wat te klein was

om op te neem

tog iewers in ons groot land nog opneembaar is

Selfs al is die nasionalistiese sentiment bevraagteken, en in die geval van anti-apartheid Afrikaanse skrywers verwerp of ondermyn, het die Afrikaanse letterkunde in hoofsaak tot een deel van die Afrikaanssprekende bevolking gespreek. Circumscribed by the walls of the cage. Op enkele uitsonderings na het die Afrikaanse letterkunde nie oor sy etniese grense gereik nie. Die letterkunde was in gesprek met die volk en die volk (dié wat die toenemend moeiliker tekste gelees het) in gesprek met die letterkunde. In die ouer Afrikaanse lettere was swart mense (maar veral ook nie-wit Afrikaanssprekendes) heel dikwels die agterryers, meelopers, die nie-gehoorde newefigure en die vertellers van "kenmerkende" humor. Hier was dikwels'n gebrek aan volle menslikheid. Ironies genoeg sou dieselfde kritiek teen latere politiek-bewuste letterkundige werke ingebring kon word. Die swart figure wat toe met meer subtiliteit ingevoer is, is dikwels met onwerklike romantisering beklee.

Die Afrikaanse literêr-kritiese praktyk sou eweneens as 'n byna geslote sisteem beskryf kon word. Die wesenskenmerk van dié praktyk is dat dit in die verlede soos die Afrikaanse geskiedskrywing nasionalisties en monolities aangedoen het, met min of geen bepaling van die relatiewe plek daarvan in die Suid-Afrikaanse kulturele konteks nie. Dié perspektief is van vroeg reeds deur toonaangewende literatore bevorder. E.C. Pienaar (1920: 20, 58-59) aan die begin van die jare twintig sien sy kritiese rol gekoppel aan die opbou van'n "nasionale selfbeeld", "nasionale selfrespek", en die taalnasionalisme van die Afrikaner.'n Ander vroeë literator, Elizabeth Conradie (1934: xix) voel so sterk oor die nasionalistiese taak dat sy' $n$ band tussen haar literêre praktyk en haar persoonlike lewe slaan. Sy sê sy skryf'n "vaderlandse geskiedenis [vanuit die] Afrikaner-standpunt, deur'n Afrikaner wat deur geboorte en opleiding ons hele verlede van die eerste dag van die Volksplanting af, intuïtief aanvoel."

In later jare sou hierdie uiterste nasionalisme getemper word met noulettende teksgebonde beskouings. Onder die invloed van die Hellinga-skool in die vyftigerjare het die Afrikaanse kritiek feitlik 
uitsluitlik teks-immanent gewerk, met beperkte belangstelling in ander literature. Rob Antonissen (1964: 1) kon in die middel-sestigerjare sê dat die Afrikaanse letterkundige geskiedskrywing hoofsaaklik 'n "kwessie van chronologiese verbandlegging" is en dat periodisering die kritikus se "fundamentele bekommernis" moet wees. Vir G.J. Gerwel (1983: 10) is die immanente teksgebondenheid in sigself ' $n$ aanduiding van die verbondenheid met die outoritêre nasionalistiese gesagstruktuur. Hy tipeer die Afrikaanse literêre praktyk as " [an] organistic model of a literary work, with its emphasis on the integration and formal organization of the elements into a coherent whole, [it] was harmonious with the authoritarian ethos of contemporary monolithic Afrikanerdom."

Teen die einde van die tagtigerjare het kritiek teen die Afrikaanse literêre praktyk so toegeneem dat Marianne de Jong (1989: 3) kon verklaar dat die Afrikaanse letterkundige geskiedskrywing "een van die beste illustrasies van die afwesigheid van 'n sosio-historiese en sosio-politieke bewussyn [is] (...) Geskiedenis word as dataversameling aangebied en ingedeel volgens ingeburgerde literêre kategorieë soos realisme, naturalisme, genre-onderskeidings, groter en kleiner skrywersfigure, ens." Ten spyte van dié bewustheid is dit opvallend dat die jongste uitgawe van Perspektief en profiel (Van Coller, 1998; 1999) beperk bly (en wel met die nodige kwalifisering) tot die halfgeslote paradigma van die Afrikaanse literêre kanon. Die Afrikaanse literatuurgeskiedenis van die afgelope een honderd jaar of wat word in hoofsaak as 'n erfenis van Afrikaner politieke, sosiale en kulturele belange aangebied, met byvoorbeeld slegs één profiel van ' $n$ swart Afrikaanssprekende skrywer, naamlik Adam Small. Tekste soos Perspektief en profiel toon die oorwig van toegang tot opvoedkundige en ekonomiese geleenthede wat wit Afrikaanssprekendes die afgelope eeu geniet het. Dit word'n verslag van eng-gedefinieerde literêre en kulturele waarde. Terselfdertyd word dit ook'n verslag van gebrekkigheid - die gebrekkige toegang tot geletterdheid, onderwys en publikasie - van die meerderheid Afrikaanssprekendes.

3

Met die vreedsame skikking tussen opponerende politieke groeperinge en die instelling van die eerste demokratiese parlement in 1994 is die dominante rol van Afrikaner-nasionalisme in die amptelike staatsdomeine finaal verbreek. Daarmee, vermoed ek, is ook'n belangrike steunfaktor vir Afrikaans verbreek; is die koudeur deurgeroes. Veral 
in Afrikaanse gemeenskappe het die veranderinge verreikende nagevolge op kulturele en politieke gebiede gehad. Afrikaner-nasionalisme (of ten minste Afrikaner-identiteit) verkeer in'n bestaanskrisis waar die verlede verreken en aanpassinge vir die toekoms gemaak moet word. Die Boetman-debat is by uitstek 'n teken van hierdie wroeginge. Die afgelope jaar is in die debat meermale die ontnugtering met politieke leiersfigure, magstrukture en na-apartheid ontwikkelinge uitgespreek. Vergelyk as eksemplariese geval Chris Louw (2001: 21-22) se ope brief aan Willem de Klerk in reaksie op dié se Afrikaners: kroes, kras, kordaat:

Ek is die bliksem in, Willem de Klerk, die bliksem in vir jou arrogansie, vir jou selfregverdigings, vir jou rasionalisasies, vir jou ontkennings, en vir jou leuens. Ek is die moer in vir die snuffie leedvermaak in jou snotskrif. As ons al jou raad volg, kan ons oorleef, ja. Maar as ons jou raad nou volg, staan ons presies waar ons sou gewees het as jy en jou hele verdoemde geslag ons nie met apartheid bedrieg het nie; en dan was ons boonop sonder die skuldlas.

(...)Wat bly vir my [die wit Afrikanerman] oor? Ek is te oud om heeltemal onskuldig te wees. Ek is te jonk om ten volle aandadig te wees. Ek is te onskuldig om verskonings te versin. Ek is te skuldig om my hande te was.

Ek is gatvol. Heeltemal, tot die keel toe, gatvol daarvoor om opdragte te vat. Eers van die apartheidspatriargie, nou van dieselfde bekeerde pilatus-patriarge en van die nuwe swart elite.

Afrikaanse skrywers het in die verlede met wisselende intensiteit, ook krities, op die verskuiwende Suid-Afrikaanse werklikheid gereageer, maar nog nooit het hulle tekste so' $n$ bruisende aar van gegriefde en ontgogelde ontboeseming raakgeboor nie. In'n groot mate definieer hierdie debat' $n$ skeuring met die verlede. Dit is'n algemeen-aanvaarde opvatting dat nasionalismes instand gehou word deur vertelling en oorvertelling: die verhale van uitverkorenheid, ontbering, opoffering en oorwinning; die mites van 'n roemryke geskiedenis (sien ook Bhabha, 1990; Manzo, 1996). Dit is ook so dat vertellinge'n nasionalisme kan ondermyn of die grense daarvan kan verskuif. Chris Louw verskuif die grense deur sy eie verhaal te vertel en hom dan uitdruklik buite die groep te plaas en aan te dring op sy individualiteit, "Maar ek is genoeg verneuk. Nou veg ek vir wat vir my van belang is. Binne die demokrasie, ja. Maar nie noodwendig saam met die voorskriftelike en 
voorsprekende en die politiek korrekte - die idiotiese - massa nie" (Louw, 2001: 22).

Waar' $n$ keuse enersyds vir individualiteit gemaak word, is daar ander stemme wat op variasies van spesiale dispensasie aandring. Die respons wissel van gebiedskeiding, militante optredes tot formele wetlike minderheidsberegtiging waar Afrikaans verskans kan word. As voorbeeld die volgende uitspraak van Z.B. du Toit (1999: 240): "Afrikaans kan' $n$ belangrike bydrae lewer om die besef te laat posvat dat minderheidsregte vir groepe eintlik' $n$ verfynde dimensie van individuele regte is waarsonder' $n$ land soos Suid-Afrika onmoontlik kan klaarkom." Die jongste aflewering van dié stroming van die debat waar' $n$ plek vir Afrikaans as openbare taal beding word, is die opeis van waarborge vir die aanbieding van Afrikaans aan voormalige Afrikaanse universiteite. Hermann Giliomee (2001: 38) reken dat "[v]ir die generering van toekomstige geslagte wat Afrikaans as publieke taal wil gebruik is die histories Afrikaanse universiteite en hulle huidige besture van deurslaggewende belang (...) [E]k glo dat Afrikaans vir die meeste mense wat tans aan die stuur van Afrikaanse universiteite staan' $n$ res publica is - 'n publieke saak wie se welsyn almal op die hart dra."

In die soeke om die behoud van Afrikaans het dit die afgelope tyd vir voorstaander-figure dwingender geword om die Afrikaanse taalgemeenskap in inklusiewe terme te omskryf. Ten spyte van die betekenisvolle aantal swart Afrikaans eerstetaalsprekers van uiteenlopende agtergronde, word in die debat uitsluitlik dikwels na bruin mense verwys. Hierdie tendens kom'n lang pad in die Afrikaanse sosiale en politieke gesprek. In die letterkunde kry die denkstroming resonansie in veral Jan Rabie se Ons, die afgod en sy latere Bolandia-reeks wat in die middeljare vyftig uitdrukking daaraan gee. In 1960 het Van Wyk Louw (1986: 623) 'n mate van intellektuele agtenswaardigheid aan die gedagterigting gegee, "Die Bruinmense is óns mense, hóórt by ons (...) [waar] in die verlede (...) die Afrikaner gely het, [was] sy Bruin broer by om saam te ly" (oorspronklike beklemtoning). Dié gevleuelde woorde het destyds nie maklik op die ore van Hendrik Verwoerd geval nie, want soos Giliomee (2001:23) argumenteer, "In die twintigste eeu het Afrikaner-nasionalisme hierdie gemeenskap [die Afrikaner] ongelukkig in eksklusiewe etniese terme gedefinieer, maar dit mag moontlik wees om die grense te verskuif om 'n nie-rassige taalgemeenskap te omsluit." Met die nawerkinge van'n oper demokratiese proses word die denkstroming toenemend gehoor in die ontplooiing van'n 
hersaamgestelde Afrikaanse identiteitskonstruk, gekenmerk deur terminologieë soos "die Afrikaanses".

Verskuiwende nasionalistiese grense, beweer Kathryn Manzo (1996: 39), kom veral voor wanneer die toekoms onseker is en die belange van die heersende groepe verander. "When the future appears uncertain or the interests of dominant classes have changed, the present is cast as unnatural and the past rewritten to suit contemporary conditions. Nations (lees ook: etniese groepe) can always be remade, by novel narratives that redefine identity and shift the boundaries between national and alien."

Die beweegrede wat Manzo aanvoer, mag'n belangrike kode wees vir die interpretasie van swart Afrikaanssprekers se stilswye en afwesigheid van deelname aan die openbare debatte rondom Afrikaans. Die suspisie onder hierdie mense mag wees dat hulle gewoon gekoöpteer sal word.

Terwyl daar onder sommige nie-Afrikaner Afrikaanssprekendes tendense is wat kleiner verbeelde stamidentiteite wil herskep en met kulturele handelinge na vervloeë assossiasies wil teruggryp, is my vermoede dat ' $n$ betekenisvolle presentasie aansluiting by ' $n$ oorkoepelende Suid-Afrikaansheid soek.

Die persepsie sou aansluit by 'n laaste stroming van die uiteenlopende response op' $n$ verbrokkelende (en heraanpassende) Afrikaner-nasionalisme, naamlik die "Tuiste vir almal-veldtog" wat bewuste aansluiting vir alle blankes en die nuwe bestel wil vestig. Volgens Carl Niehaus, een van die aanvoerders van die veldtog, is dit' $n$ "niepartydige inisiatief van'n groep wit Suid-Afrikaners wat glo dat dit nodig is vir blankes om die skade en gevolge van apartheid te erken, en om by te dra om rassisme te beveg en om agtergeblewe gemeenskappe te bemagtig" (aangehaal in Beeld, 11 Desember, 2000: 1). In die Afrikaanse koerante is die veldtog getref deur ' $n$ vlaag negatiewe briewe en berigte, terwyl vanuit swart geledere hierdie ootmoedigende benadering groter aanklank gevind het. Henry Jeffreys en Sekola Sello, rubriekskrywers van die dagblad, Beeld, reageer onderskeidelik soos volg op die veldtog. Vir Jeffreys (2000) is dit bewonderingswaardig dat daar' $n$ groep mense is wat openlik sê hulle het berou oor apartheid, erken dat hulle regstreeks of onregstreeks daardeur bevoordeel is en hulle daartoe verbind om hul "vermoëns, middele en energie individueel en gesamentlik aan te wend om rassisme met wortel en tak uit te roei en'n nie-rassige gemeenskap te bevorder wat tot voordeel strek van alle Suid-Afrikaners." 
Sello (2001) slaan 'n verband tussen die Afrika renaissance-gedagterigting en die Tuiste-vir-almal-aksie en omskryf in duidelik terme 'n oorkoepelende Afrika-gesindheid,

Vir my is die Afrika-renaissance een van die belangrikste uitdagings waarvoor Afrikane hierdie eeu te staan gekom het. Diegene wat daarop aanspraak maak dat hulle Afrikane is, moet ophou kerm en kla, en deel word van hierdie beweging (...) [E]k daag daardie wit landgenote van my wat sê hulle word polities gemarginaliseer of hulle beskou die Afrika-renaissance as nog 'n anti-wit-voertuig om hulle mee in die see te jaag, uit om weer te dink.

Hierdie uiteenlopende reaksies op die veranderende Suid-Afrikaanse realiteit is nie net van terloopse belang nie. In die universiteitsomgewing help hierdie debatte om vorm en rigting aan Departemente Afrikaans te gee. Die krisis in Afrikaner-nasionalisme,'n ontluikende Suid-Afrikaanse gesindheid en die vestiging van'n globaliserende visie gaan in die afsienbare toekoms ook die ontplooiing van taaldepartemente beïnvloed.

4

Die voorafgaande is ' $n$ konteksstelling van die multidimensionele problematiek waarmee Afrikaanssprekendes en Departemente Afrikaans aan universiteite hulle bevind. Hierdie tyd van ingrypende politieke, sosiale, maar veral ekonomiese en tegnologiese verandering, dwing die Afrikaanse literêre kritikus om sy vakgebied indringend te herdefineer.

In hoofsaak kom al die konseptuele voorstelle wat ek hier maak, neer op die nastreef van' $n$ ruimer kurrikulumbeskouing, 'n ruimer Afrikaansheid, maar ook'n ruimer Suid-Afrikaansheid. Die grootste uitdaging in die ontplooiing van'n Departement Afrikaans in ons tydsgewrig is om weg te beweeg van'n verkalkte letterkundige praktyk, iets wat Bhabha (1994: 9) "the estranging sense of the relocation of the home and the world - the unhomeliness - that is the condition of extra-territorial and cross-cultural initiations" noem. Dit beteken naas gevestigde praktyke 'n doelbewuste skakeling met ander SuiderAfrikaanse, Afrika en internasionale tradisies;' $n$ verbreding van ons navorsingspraktyke om byvoorbeeld 'n slag weer krities na ons geinstitusionaliseerde literêre modelle, benaderings en ingesteldhede te kyk; om erns te maak met die eise van ons eietydse kulturele praktyke. 
- In'n letterkundige tradisie wat soos hierbo kortliks aangedui is, in die verlede uitermate etniese gebondenheid aangemoedig het, is die eerste taak met die opleiding van jonger kritici en studente die inskerping van 'n bewuste opposisionaliteit. Die belangrike rol van die opposisionele kritikus is die konstante onderbreking en disrupsie van die letterkundige praktyk. In hierdie geval sou dit die doelbewuste onderbreking van die Afrikaanse kanon wees. Ons sal die student tot' $n$ bewustheid moet lei om die geslotenheid, die engheid en die beperktheid van die Afrikaanse letterkunde te oorstyg. Edward Said beskryf dié soort kritiek-beoefening as ' $n$ selfbewustheid oor verskille met ander denke, kulturele aktiwiteite of metodiek. Opposisionele kritiek word gekenmerk deur verset of opposisie teen kulturele of sosiale hegemonie: “In its suspicion of totalizing concepts, in its discontent with reified objects, in its impatience with guilds, special interests, imperial fiefdoms and orthodox habits of mind, criticism is most itself and, if the paradox can be tolerated, most unlike itself at the moment it starts turning into organized dogma" (Said, 1984: 29).

- Die geneigdheid in die Afrikaanse letterkundige kringe om in hoofsaak gekanoniseerde en kanoniseerbare tekste te ondersoek, lei tot 'n uiterste verskraling van die potensiële ondersoekterreine van ons vakgebied. Ten spyte van oproepe in die verlede om die veelvoud van Afrikaanse uitdrukkingspraktyke te ondersoek, bly die oorhoofse Afrikaanse letterkundige ingesteldheid beperk en anemies. Deel van'n oper werksaamheid vereis'n rigting weg van'n essensialistiese literatuurbeskouing na' $n$ beskouing wat literatuur as' $n$ histories gekonstrueerde gegewe ondersoek. Stuart Hall (aangehaal in Bennett, 1986: 238) stel met reg dat in die proses van navorsing die hiërargie die teiken van ondersoek moet word:

Why is it that the text, the many texts, the many signifying practices which are present in any social formation have yielded, as the administered curriculum of literary studies, these ten books at the top; then these twenty books with a question mark above them; then those fifty books which we know about but which we only need to read very quickly; and then those hundreds and thousands of texts nobody ever reads. That hierarchy itself, which constitutes the selective tradition in literary studies, becomes the first object to be interrogated. 
- Dié ingesteldheid sal kritici in staat stel om nie net die onstabiliteit van literêre waarde en die konstruksie van literêre kanons krities te beskou nie, maar om ook daadwerklik die uitgeslote stemme, die sosiaal en politiek-gemarginaliseerdes te registreer en te leer vertolk (sien ook Bhabha, 1994: 9). Dit behels ook'n beskouing wat erns maak met moderner tekstuele praktyke soos die televisie en die internet.

- Soos hierbo aangedui, is'n toonaangewende reaksie vanuit sekere kringe van Afrikaanssprekendes' $n$ groot mate van behoudenheid. Vir Departemente Afrikaans om in hierdie tyd te oorleef, is' $n$ bewuste oorstyging van die etniese geseteldheid van Afrikaans nodig. Dit is' $n$ bewustheid dat Departemente Afrikaans effektiewe programme sal moet ontwikkel om verby die historiese beperkinge van Afrikaans te kom. Departemente Afrikaans kan nie ingebed bly in vakkundige programme wat geen bewuste poging aanwend om die juk van gereïfiseerde vorme van Afrikaner-nasionalisme te oorstyg nie.

- Departemente Afrikaans kan nie bly voortbestaan sonder' $n$ bewustheid van 'n ruimer Suid-Afrikaanse verband nie. Een universiteit het hul eerste formele vergelykende Suid-Afrikaanse letterkundekursusse reeds twee dekades gelede ingevoer en by'n ander word volgehoue navorsing in Suider-Afrikaanse letterkundes en tale gelewer. In die jongste tyd word Departemente Afrikaans by ' $n$ aantal inrigtings administratief onder Skole vir Tale ingedeel. Ten spyte van die ontwikkelinge vind daar, op basis van gepubliseerde plaaslike navorsing, weinig ten opsigte van aktiewe vergelykende programme plaas. Te oordeel aan publikasietendense in internasionale tydskrifte is dit eerder buitelandse akademici, of nuwe emigrés vanuit Suid-Afrika wat vorm aan die Suider-Afrikaanse ingesteldheid gee (vergelyk byvoorbeeld Attridge and Jolly, 1998; Jolly, 1996). Die een plaaslike navorser, Michael Chapman, wat met sy Southern African Literatures die terrein in sy volle omgang wou omskryf, kon nie werklik reg aan die volle terrein laat geskied nie. As die uitbreiding van ons vakgebied, indringende navorsing en die integrasie van ons kundighede 'n erns is, sal navorsers aan plaaslike Departemente Afrikaans vir hulself'n aktiewe (en koöperatiewe) rol in die verband van Suider-Afrikaanse letterkundes en tale moet toesê. 
- Met die gerugte van die totstandkoming van'n Afrika-unie staan ons op die vooraand van ontwikkelinge wat die potensiaal het om ingrypend die wyse waarop ons oor onsself dink, na onsself kyk, en ander ervaar, te kan verander. Dit is ontwikkelinge waarvan ons die eerste spore nog nie werklik kan ontsyfer nie. Naas verskerpte pogings om Afrikaans in die konteks van Suider-Afrikaanse letterkundes te ondersoek, mag ons nie die inpassing van Afrikaans in Afrika-verband agterweëlaat nie. Die isolering van die Afrikaanse letterkunde, nie net van Suid-Afrikaanse- maar ook van Afrikaletterkundebeskouinge, veroorsaak dat een van die sterkste Afrikaletterkundes doodgewoon nog nooit sinvol aan 'n breër Afrikaleserspubliek bekendgestel is nie. In van die toongewende oorsigte van letterkunde in Afrika soos byvoorbeeld Oyekan Owomoyela se A History of Twentieth-century African Literatures is daar geen enkele verwysing na die Afrikaanse letterkunde of na Afrikaans nie. Dit is eers met The Companion to African Literatures (Killam \& Rowe, 2000) dat'n meer sistematiese blik, alhoewel heeltemal onvolledig, op die produksie van Afrikaanse letterkunde in Afrika-verband gegooi word.

- Met die globaliserende tendense wat op allerlei vlakke benewens die ekonomie waarneembaar is, het dit belangrik geword dat ons in Departemente Afrikaans die ontplooiing en ontwikkelinge in letterkundes uit soortgelyke kontekste moet ondersoek. In die verlede het ons om historiese (en koloniale verbintenisse) erns gemaak met letterkundes uit die Europese lae lande. Vernon February (1991: 10) het reeds vroeër op die belang van so'n verbreide benadering gewys, "[E]k betoog vandag dat die studie van $\mathrm{Ne}-$ derlands (...) nie losgekoppel moet word van Afrikaans nie, maar anders benader moet word op grond van die feit dat in Suriname, de Nederlandse Antillen en in Indonesië daar 'swart' skrywers, digters en wetenskappers is wat deur hulle literêre corpus die Nederlandse taal en letterkunde op'n opwindende wyse 'maatschappelijk relevant' kan maak." Dit is op hierdie wyse dat Afrikaans, Afrikaanse letterkunde en Suid-Afrikaanse kundiges in Departemente Afrikaans werklik kan bydra tot internasionale mededingendheid. Soos Frantz Fanon (1982: 199) gesê het, “National consciousness, which is not nationalism, is the only thing that will give us an international dimension." 
Afrikaans en die Afrikaanse letterkunde in Departemente Afrikaans staan op'n draaipunt. Die verskansing van Afrikaans of politieke bedinging vir' $n$ uitsonderlike posisie vir Afrikaans word gedryf deur belangegroeperinge wat dikwels teruggryp na'n ouer bestel toe die posisie van die taal gelykgestel is aan politieke beheer. Afrikaanssprekendes en daarmee saam Departemente Afrikaans sal kreatiewer prosesse moet ontwikkel om ook deur Afrikaans die wêreld ten volle te beleef en te beskryf. Teen die agtergrond van die krisis wat sommige Afrikaanssprekendes ervaar, is dit my oortuiging dat navorsers van die Afrikaanse letterkunde daadwerklike pogings moet aanwend sodat in die woorde van die jonger Breytenbach die vakgebied, "tog iewers in ons groot land nog opneembaar is."

\section{Aantekeninge}

1 Hierdie artikel is 'n hersiene weergawe van my intreerede, "Om te leef in Afrika: oorlewing, saambestaan en die Suid-Afrikaanse letterkunde", gelewer by die aanvaarding van die leerstoel in Afrikaans aan die Universiteit van Pretoria op 19 Julie 2001. My dank aan Viola Milton, Carol-Ann Mohamed, Piet Roodt en Victor Webb vir hul kritiese meelewing.

2 In die artikel word Suid-Afrikaanse etniese nomenklatuur aangewend. Die gebruik daarvan beteken nie die aanvaarding van etniese klassifikasie of ordening nie. "Swart" word hier in die generiese politieke sin van die begrip gebruik.

\section{Bronnelys}

Attridge, Derek \& Jolly, Rosemary. (Eds.) 1998. Writing South Africa: Literature, Apartheid, and Democracy, 1970-1995. Cambridge: Cambridge University Press.

Bennett, Tony. 1986. Marxism and popular fiction. In Humm, P., Stignant, P. \& Widdowson, P. (Eds.) Popular Fictions: Essays in Literature and History. London, New York: Methuen.

Bennington, Geoffrey. 1990. Postal politics and the institution of the nation. In Homi K. Bhabha. (Ed.) Nation and Narration. London, New York: Routledge, 121-137.

Bhabha, Homi K. 1990. Introduction: narrating the nation. In Homi K. Bhabha (Ed.) Nation and Narration. London, New York: Routledge, 1-7.

- 1994. The Location of Culture. London, New York: Routledge.

Breytenbach, Breyten. 1981². Kouevuur. Emmarentia: Taurus.

Coetzee, Ampie. 1988. Marxisme en die Afrikaanse letterkunde. Kasselsvlei: Kampen.

Conradie, Elizabeth. 1934. Hollandse Skrywers uit Suid-Afrika: 'n Kultuur-historiese studie deel 1 (1652-1875). Pretoria: J. H. de Bussy.

Chapman, Michael. 1996. Southern African Literatures. London, New York: Longman.

De Jong, Marianne. 1989. 'n Ander Afrikaanse letterkunde: Marxistiese en sosiaalgerigte teksopvattinge in Afrikaans. Pretoria: Raad vir Geesteswetenskaplike Navorsing.

Du Toit, Z.B. 1999. Die nuwe toekoms - 'n perspektief op die Afrikaner by die eeuwisseling. Pretoria: J.P. van der Walt.

Fanon, Frantz. 1982. Trans. Constance Farrington. The Wretched of the Earth. Harmondsworth: Penguin. 
February, V.A. 1991. Laat het ons ernst wezen: die verhouding Afrikaans-Nederlands Intreerede. Bellville: Universiteit van Wes-Kaapland.

Gerwel, G.J. 1983. The Politics of Language and Literary Studies - An Inaugural Lecture. Bellville: University of the Western Cape.

Giliomee, H. 2001. Die taal- en kulturele uitdagings van die historiese Afrikaanse universiteite in Suid-Afrika. D.F. Malherbe-gedenklesing 20. Acta Varia. April 2001: 1

Hobsbawm, E.J. $1992^{2}$. Nations and Nationalism since 1780. Cambridge: Cambridge University Press.

Jeffreys, Henry. 2000. As ek wit was Carl Landgenote se belydenis-dilemma. Beeld, 15 Desember, 14.

Jolly, Rosemary Jane. 1996. Colonization, Violence, and Narration in White South African Writing: André Brink, Breyten Breytenbach, and J.M. Coetzee. Athens: Ohio University Press, Johannesburg: Witwatersrand University Press.

Killam, Douglas \& Rowe, Ruth (Eds.) 2000. The Companion to African Literatures. Oxford: James Currey; Bloomington: Indiana University Press.

Lerner, Adam J. 1993. Introduction. In Marjorie Ringrose \& Adam J. Lerner. (Eds.) Reimagining the nation. Buckingham, Philadelphia: Open University Press, 1-5.

Lindfors, Bernth. 1997. African Textualities: Texts, Pre-Texts and Contexts of African Literature. Trenton / Asmara: Africa World Press, Inc.

Louw, Chris. 2001. Boetman en die swanesang van die verligtes. Kaapstad: Human en Rousseau.

Louw, N.P. van Wyk. 19787. Die Dieper reg : 'n spel van die oordeel oor ' $n$ volk. Kaapstad: Tafelberg.

. 1986. Versamelde Prosa 2. Kaapstad: Human en Rousseau.

. 1981. Versamelde Gedigte. Kaapstad: Tafelberg / Human en Rousseau.

Manzo, Kathryn A. 1996. Creating Boundaries: The Politics of Race and Nation. Boulder, London: Rienner.

Mphahlele, Ezekiel. 1974². The African Image. London: Faber \& Faber.

Owomoyela, Oyekan. (Ed.) 1993. A History of Twentieth-Century African Literatures. Lincoln, London: University of Nebraska Press.

Pienaar, E.C. $1920^{2}$. Taal en Poësie van die Twede Afrikaanse Taalbeweging. Kaapstad: De Nationale Pers.

Said, Edward. 1984. The World, The Text, The Critic. London: Faber \& Faber.

Scholtz, A.H.M. 1995. Vatmaar, 'n Lewendagge verhaal van 'n tyd wat nie meer is nie. Kaapstad: Kwela Boeke.

Sello, Sekola. 2001. Uitdaging vir wittes: Word deel van Afrika-renaissance. Beeld, 27 Februarie, 10.

Spivak, Gayatri, Chakravorty \& Haraysm, Sarah. (Eds.) 1990. The Post-colonial Critic: Interviews, Strategies, Dialogues. London: Routledge.

Steyn, J.C. 1998. Van Wyk Louw: 'n lewensverhaal (2 dele). Kaapstad: Tafelberg.

Van Coller, H.P. (Red.) 1998, 1999. Perspektief en profiel - 'n Afrikaanse literatuursgeskiedenis (2 bande). Pretoria: J. L. van Schaik.

Van Wyk, Johan. 1995. Constructs of Identity and Difference in South African Literature. Durban: CSSALL.

Willemse, Hein. 1996. The Invisible Margins of Afrikaans Literature. In Robby Kriger and Ethel Kriger. (Eds.) Afrikaans Literature: Recollection, Redefinition Restitution. Matatu 15-16. Amsterdam, Atlanta: Editions Rodopi, 91-102. 